\title{
Food Adulteration: A Serious Public Health Concern in Bangladesh
}

\author{
Md. Arifur Rahman ${ }^{1 \psi}$, Md. Zakir Sultan ${ }^{2 \psi}$, Mohammad Sharifur $\operatorname{Rahman}^{3 \psi}$ \\ and Mohammad A. Rashid ${ }^{3}$ \\ ${ }^{1}$ Department of Pharmacy, Daffodil International University, Dhaka-1207, Bangladesh \\ ${ }^{2}$ Centre for Advanced Research in Sciences, University of Dhaka, Dhaka-1000, Bangladesh \\ ${ }^{3}$ Department of Pharmaceutical Chemistry, Faculty of Pharmacy, University of Dhaka, Dhaka-1000, Bangladesh
}

Received: July 07, 2014; Accepted: August 05, 2014

\begin{abstract}
Adulteration of foods has become a national issue. The problem is not only ignoring the human rights for safer food but also endangering public health seriously with numerous acute and chronic diseases. Our future generation will be seriously affected with vulnerable physical and mental growth inflicted by food adulteration. This paper describes the impact of consumption of adulterated foods on human health and the roles of the concerned authorities to eradicate it. The key objective of this paper is not to blame or undermine anyone. We intend to inform the current scenario of food adulteration and wish to bring a positive change through proper measures by the concerned regulatory authorities.
\end{abstract}

Key words: Food adulteration, food safety, toxicity, public health, human rights

\section{Introduction}

In the time of indivisibility, interdependence and interrelatedness of human rights, the right to safe food acclaims significant bearing on the right to health, right to food and most importantly right to life (Leon, 2014). But now-a-days in Bangladesh, human rights for safe food are ignored indiscriminately. As per the news, features and articles published in different newspapers in Bangladesh, most of the foods manufactured or processed are either adulterated in varying degrees or unsafe for human consumption.

Adulteration in a broad and legal sense is the debasement of any article. So, adulteration of food means substandard foods, which fails to comply with the definition of safe food by the Food and Agriculture Organization (FAO) and World Health Organization (WHO). Anyway, adulteration of food and food products can be unintentional and/or intentional. Unintentional adulteration includes naturally occurring substandard foods, due to lack of rainfall, drought, poor storage condition, etc. On the other hand, intentional adulteration is done with the intent to defraud or cheat the consumers. The addition of wheat flour to powdered ginger with enough capsicum to restore the pungency and enough curcuma to maintain the natural color is a typical example of intentional adulteration. This is also known as sophistication, which means no stone is left untouched to produce a food item which would probably look even better than a naturally grown/produced food and food products. This is more serious, which is affecting the health of our citizens, including much our innocent children.

The problem of adulteration persists at every level of food from preparation to consumption. Most of the food manufacturers, processors, restaurant owners and so forth are all involved in one way or another in this unethical practice of adulteration. Foods are adulterated by using various harmful chemicals and toxic artificial colors. Rotten and perishables foods are stored, sold and served to consumers. Uses of poisonous chemicals in perishable foods are evident in highest degrees which are endangering the lives of the people (Derek, 2013).

The supply of unsafe foods is negatively contributing to the public health seriously with numerous acute and chronic diseases. This paper has focused the blindfolding of the traders and retailers to social commitment and the limitation of law implementation agencies to combat the current food security problems prevailing in Bangladesh.

Correspondence to: Mohammad Abdur Rashid; Tel.: 880-2-9661920, Ext. 8137; Fax: 880-2-9667222; E-mail: rashidma@du.ac.bd.

${ }^{\Psi}$ These authors have equal contribution 


\section{Current scenario of food adulteration}

Unsafe foods are responsible for a number of diseases in the entire world. Bangladesh, a member of Least Developed Countries (LDCs) of South Asia, is not an exception in this case. Consumption of unsafe food is a serious threat to public health in Bangladesh for the last couple of decades. A survey conducted by the Institute of Nutrition and Food Science, University of Dhaka in early 1980s revealed that inadequate diets and intake of adulterated foods are responsible for the malnutrition of $60 \%$ of the people of Bangladesh (http://www.assignmentpoint.com). The Institute of Public Health (IPH) in Dhaka and the World Health Organization (WHO) in their joint study on food adulteration in 1994 tested 52 street vendors and found that all of their food samples were contaminated with different types of pathogenic microorganisms (Badrie et al., 2006). They also conducted another study in 2003 in Dhaka city and found that $96 \%$ of sweetmeats, $24 \%$ of biscuits, $54 \%$ of breads and $59 \%$ of ice creams were extensively adulterated (Rahman et al., 2005). This study also revealed that over the preceding decades, some $50 \%$ of the food samples tested in IPH laboratory were marked as adulterated (Badrie et al., 2006). Similarly, a recent official statistics published by the Ministry of Health and Family Welfare (MOHFW) of the Government of the People's Republic of Bangladesh $(\mathrm{GoB})$ revealed that nearly half of the food samples have been found adulterated when tested by the IPH from 2001 to 2009 (Directorate General of Health Services, 2012). This GoB statistics indirectly demonstrated that the situation of the prevailing food adulteration concerns in Bangladesh has not been improved over the past 10 years.

A recent report by the 'Poribesh Bachao Andolan' disclosed that about 7.9 million (79 lakh) people in South Asia die every year by non-contagious diseases and food adulteration is marked as one of the most important reasons. The report also warned that if this food adulteration cannot be prevented now, it will affect the mental growth of our next generation (The Daily Observer, 22 June 2014).

According to a report of the Daily Star published on 11 August 2011, the basic food items on the market like rice, fishes, fruits, vegetables and sweetmeats are adulterated with hazardous chemicals in an indiscriminate manner. A random survey by the Public Health Laboratory of Dhaka City Corporation in 2004 indicated that more than $76 \%$ of food items on the market were found to be adulterated and the level of food adulteration varied $70 \%$ to $90 \%$ (The Daily Star, 11 August 2011). Very recently, Transparency International Bangladesh (TIB) disclosed that at least 4.5 million people were directly affected by the consumption of tampered foods in Bangladesh (The Daily Star, 22 March 2014). According to a report (The Daily Star, 28 April 2014), The Food and Agriculture Organization (FAO) of the United States tested fruits, vegetables, milk and milk-products in a government laboratory and revealed that all of the tested food stuffs contained banned pesticides that pose serious health hazards. The presence of toxic substances in these samples was about 20 times more than that set by the European Union. Still the degree of adulteration is rising alarmingly in an epidemic manner (Mahfuz and Mahin, 2014; Mahfuz, 2014; Rimon, 2014; Parvez, 2014).

\section{Examples of some food adulteration}

Food items that are commonly adulterated include fruits, vegetables, milk, fishes, sweetmeats, rice, wheat, meat, oil, ghee, spices, egg, soft drink, juice powder, baby foods and so on (Mahfuz, 2014). Fruits are adulterated with calcium carbide, ethephon, formalin, injections of colors and sweeteners. Vegetables are adulterated with formalin and toxic dyes while fish with formalin (The Daily Star, 01 November 2009). According to the findings of the National Food Safety Laboratory of the Government of the People's Republic of Bangladesh (NFSL), some regular food items like carrot, bean, tomato, banana, mango etc. are contaminated with toxic pesticides. DDT (Dichloro diphenyl trichloroethane) is used in dried fish at a higher concentration. Milk is adulterated with formalin, addition of dirty water, removal of fat, addition of wheat flour or powder milk, sorbitol and detergent as thickening agents. Powder milk is adulterated with melamine and banned pesticide (The Daily Star, 30 January 2007). Aldrin was also found in milk and milk products (Nath, 2014). Meat is often adulterated with formalin and toxic red color. Ghee is adulterated with animal fat or palm oil (The Daily Star, 12 July 2007; 7 December 2008). Vegetable oils are adulterated with cheap non-edible oils. Rice is adulterated with stone particles, urea and artificial colors. Chili powder is adulterated with brick dust and sudan red color, while 
turmeric powder is adulterated with metanil yellow and colored chalk powder. Black pepper is adulterated with dried papaya seeds and honey is with colored sugar syrup. Tea is adulterated with exhausted tea leaves and saw dust. Puffed rice (muri) is adulterated with hydrose (sodium hydro sulfite) and urea to make it whiter and bigger in size (The Daily Star, 28 July 2011; 4 August 2012; Mahfuz and Mahin, 2014; Mahfuz, 2014). Sweetmeats are adulterated with toxic sodium cyclamate, colors and formalin (Mahfuz and Mahin, 2014; Mahfuz, 2014). Jilapi (a kind of sweetmeat) is adulterated with burnt engine oil and toxic textile dyes (Farooque, 2014).

Packaged and bottled drinks and fruit juices are manufactured with harmful chemicals and ingredients. Cakes, biscuits, sweetmeats, etc. are made with rotten flour, rotten eggs, burnt oil, dirty water, date-expired imported powder milk, textile dyes, chemicals and essence at unhygienic places (Khan, 2014). Textile dyes although highly injurious to health are randomly used in many types of food items as coloring agents. Papayas and bananas are artificially ripened by carcinogenic chemicals. In the fasting month of Ramadan, iftar (breaking of fast) items like peaju, alur chop, kabab etc. are prepared by using burnt oil, which severely affects the digestive system (Mahfuz and Mahin, 2014; Mahfuz, 2014; Rimon, 2014; Parvez, 2014). Drinking water in bottle and jar is adulterated by impure, contaminated, unhygienic pond water, WASA (Water Supply Authority) supplied city water and so on (Rimon, 2014).

Recently it has been reported that there has been bumper production of pineapple in Bangladesh this year (The Independent, 19 Aug 2014) but it is very unfortunate that some growers were seen to spray formalin and other chemicals to their products (The Daily Star, 20 August 2014).

\section{Major causes of food adulteration}

Adulteration of food items began a couple of decades ago and this practice is increasing day by day. Dishonest traders, importers and manufacturers, cultivators and processing agencies are involved in these unethical practices. There is no paucity of laws and regulations to control adulteration of food in Bangladesh such as Bangladesh Standard Testing Institute (BSTI) Ordinance of 1985, and the Pure Food Ordinance of 2005. These rules encompass the offences like fake licenses, poor quality of food, substandard infrastructure and lack of hygiene, food adulteration, food impurity, incorrect information on food packages, selling products with expired date etc. However, the problem lies in its sustained and appropriate implementation by the credible authorities. Occasionally, the regulatory authorities become active and conduct mobile courts to penalize sellers and/ or producers for selling adulterated food products for a short period of time.

Besides, scarcity of test reagents, instruments and manpower is very much noticeable. In fact, the Ministry of Health and Family Welfare, Ministry of Food, Ministry of Agriculture, Local Government Division, Ministry of Fisheries and Livestock, Ministry of Commerce, Ministry of Industries, Ministry of Home Affairs and Ministry of Information should play the vital role in food security issues but as per the news published in various newspapers they are unable to do it probably due to lack of manpower, motivation and many other reasons.

\section{Please think and change your mind set}

We would like to bring some very simple and relevant examples of adulterated food and food products which we consume regularly, but do not try to realize the problems. If we think the followings then hopefully we all can make a difference:

(a) Whole milk is normally sold in the market at 6070 taka/liter. If we try to convert it to evaporated milk or more popularly condensed milk then about $80 \%$ of the moisture need to be vaporized. So to get a can of condensed milk (390 g) we need at least 2-2.5 liters of whole milk, which will cost about 150 taka. If this is the situation then how can we expect to get a can of condensed milk with only 50-55 taka? Should we get condensed milk of acceptable quality? The answer is no.

(b) Apples are sold in the market at 120-150 taka/kg. How much fresh juice can we obtain from $1 \mathrm{~kg}$ of fresh apple? If we realize this then why do we expect to get about $200 \mathrm{ml}$ of any fruit juice with 20 taka only. Again, we need to change our attitudes and expectations.

(c) If we try to dissolve chili powder in water, it will never give a bright red colored solution immediately. This is because not $100 \%$ of the powder chili will undergo solubilization in water. So how do we get immediate 
bright red color of some packed chili powder? Because it contains unauthorized textile color or colors which have been banned long time ago from the food color category.

(d) Saffron is a popular coloring agent which is used in preparing various sweetmeats, especially zorda (a special type of desert with bright yellow color) which is very common in any wedding party. It looks great and taste is also good. But how does it get its bright yellow color? Many of us consider that saffron has been used as the coloring agent. But saffron is too expensive to be used; about US \$2000-10000 per pound depending upon the quality. Although cheaper varieties are available, still that will be too much if we compare with the so called food grade (?) yellow color that we frequently use in cooking. So can we still think that saffron is always used in zorda? Again the answer is no.

(e) There are many examples of similar common phenomena, which we use in our daily life but never think about the cost and quality together. However, it is important to note that even we pay high price there is no guarantee of getting quality product in our country.

\section{Impacts of food adulteration on human health}

Consumption of adulterated food items may cause asthma, sore throat, larynx constriction, bronchitis, skin infections, allergic reactions, diarrhea, hematuria, circulatory failure, numbness, dizziness, kidney failure, stomach cancer, liver cancer, nervous disorders and many other diseases (The Daily Star, 28 July 2011). Researches have revealed that consumption of formalin directly through food can cause different types of cancers, especially the lung cancer (Wooster et al., 2005; WHO, 1988). After consumption of adulterated food items, thousands of people are becoming sick. Children are the worst victims. About three million people suffered from diarrhea during 2005-2009 and about $15 \%$ of children died in 2011 as reported by the Directorate General of Health Services (Nath, 2014). The long term effects are also very severe especially the incidence of renal failure, liver damage and cancer which are increasing alarmingly in Bangladesh. Heavy metals, such as lead, chromium and arsenic accumulate in the body that might cause kidney and liver damage and develop abnormality among children (Khan, 2014).
Textile dyes for short term use may cause diarrhea and gastrointestinal problems but in the long run, these materials accumulate in the body with serious health hazards.

The burnt oil developed after repeated cooking severely affects the digestive system. In case of very young children, the liver is not matured enough to metabolize and break down the toxins. This may affect the development of immune system. So, our children are at high risk due to such adulteration (Dhaka Mirror, 23 August 2009; The Independent, 24 February 2014).

According to the general information regarding food risk published by WHO, human exposure to chemicals at toxic levels as well as nutritional imbalances are known or suspected to be involved in causing cancer, cardiovascular diseases, kidney and liver dysfunctions, hormonal imbalance, reproductive disorders, birth defects, premature births, immune system suppression, musculoskeletal diseases, impeded nervous and sensory system development, mental health problems, urogenital diseases, old-age dementia and learning disabilities. Therefore, the protection of diet from these hazardous conditions is essential to protect public health (WHO, 2009).

\section{Ways to prevent food adulteration}

Many countries around the world are concerned about handling issues with the food adulteration. Food and Drug Administration (FDA) was established in the United States in 1906 and Food Safety and Standard Authority started functioning in India in 2011 with trained personnel with the ability of enforcement of laws and understanding of its complications from scientific knowledge and background. The question of human rights, accurate detection of offence and also extent of punishments are the prime issues to counteract the adulteration problems. In our country, Bangladesh Standard and Testing Institute (BSTI) was established in 1985 and Consumer Right Act, 2009 was approved by the parliament with the functioning of a department under the guidance of a council headed by the commerce minister. Sometimes, the law enforcing agencies maintain strong vigilance to detect such cases of adulteration. In fact, there are arrangements to detect the defaulters with the laboratory tests and enforce the existing laws to combat the menace but concerted efforts and manpower are inadequate. Early in June 2014, the 
Dhaka Metropolitan Police also started an anti-formalin drive in and around the capital to check formalin in seasonal fruits and destroyed tonnes of fruits, mainly mangoes and litchis (Daily Prothom Alo, 1 July 2014). At that time a formalin-checking operation was started by a joint team of BSTI and mobile court occasionally. There are at least two dozen other chemicals used by unscrupulous traders in food items for food adulteration which should also be monitored.

FAO Food Safety Project Team has analyzed gaps, overlaps, strengths and weaknesses in the currently available food inspection and enforcement systems and recommended ways to strengthen food inspection and enforcement services for domestically produced and imported foods (FAO, 2010).

Many suggestions have already been emerged in curbing adulteration of foods (The Independent, 24 February 2014; Dhaka Tribune, 15 March 2014; The Financial Express, 21 August 2014). Following concerted efforts might be beneficial for preventing food adulteration.

1. Sustainable development of mass awareness among people against the consequence of food adulteration on long term health.

2. Severe and exemplary punishment to the food contaminators. Life imprisonment or capital punishment may be considered depending upon the degree of offences and ultimate effect.

3. Strengthening food inspection service with skilled manpower and valid analytical instruments as well as proper enforcement of relevant laws in a sustainable manner.

4. Lowering the safety limit of the amount of pesticide and other toxicant residues in food items as per international guidelines.

5. Educating the primary- and secondary level students regarding the fatal impacts of food adulteration through academic curriculum.

6. Training of farmers on the use of alternative and safe chemicals by the zonal agricultural department.

7. Promotion of ethical practices among the business community with direct participation of the business leaders.
8. Active role of the consumer rights groups against this menace.

9. Implementation of all international agreements and protocols on safe food by the government through concerned ministries.

10. Involvement of the health related scientists from all universities and institutes to cross-check the market products time to time through laboratory analysis by independent research with the help of governmental support and grant.

11. Declaration of reward by the government for providing information regarding food adulteration syndicate, factory, selling points, supply chain, etc.

\section{Laws against food adulteration}

The government should take adequate measures for better coordination among law enforcement and other concerned agencies, to check food adulteration and ensure safe food. The provision of exemplary punishment should be inserted into the food act. There are several laws and regulations to control adulteration of food in Bangladesh such Pure Food Ordinance, 1959 and Pure Food Rules, 1967; The Animals Slaughter (Restriction) and Meat Control (Amendment) Ordinance, 1983; Bangladesh Standard and Testing Institution Ordinance 1985 (amended as Bangladesh Standard and Testing Institution Amendment Act 2003); Destructive Insects and Pests Rules (Plant Quarantine) 1966, amended up to 1989; Agricultural Produce Market Act 1964 (revised in 1985); Fish Protection and Conservation Act, 1950 (latest amendment in 1995); Marine Fisheries Ordinance 1983 and Rules 1983; Fish and Fish Products (Inspection and Quality Control Ordinance, 1983; Fish Products (Inspection and Quality Control) Rules' 1997; The Essential Commodity Act 1957, 58, 64; The Food or Special Courts Act 1956; The Food Grain Supply (Prevention of Prejudicial Activity) Ordinance 1956; The Pesticides Ordinance 1971 and The Pesticide Rules-1985. Bangladesh Food and Nutrition Policy 1997 and National Policy of Nutrition 1997; Bangladesh Food Policy 1998; Comprehensive Food Security Policy 2001 and New National Food Policy 2006; National Agriculture policy 1999; Bangladesh Health Policy 2002. The degree of punishment in the existing act of Bangladesh Standards and Testing Institution (BSTI) regarding food adulteration 
is maximum three years imprisonment or Tk. 2 lakh fine or both, which is not enough to prevent food adulteration. The government should implement all international agreements and protocols on food security and the standards of safe food regarding import and export to check food adulteration (Dhaka Tribune, 15 March 2014).

Recently, the cabinet of the Government of the People's Republic of Bangladesh approved the Formalin Control Act 2014 on June 30, 2014 with provision for a maximum punishment of lifetime jail and fine of Tk. 20 lakh or both to stop misuse of formalin. According to the law, it is mandatory for traders to have licenses to import, stock, sell and market formalin. The law provides for maximum 7 years imprisonment or 5 lakh taka fine or both in case of violation of the terms of formalin license and stockpiling of formalin illegally at houses, offices, business establishments or in vehicles. The law also has a provision of maximum 10 years imprisonment or 20 lakh taka fine for possessing equipment for formalin production. Police can arrest any offender without court permission if a case is filed under the act. For immediate implementation, the authorities will use mobile court drives. Besides, formalin control committees will be formed in every district and upazilla to supervise enforcement of the act (The Daily Star, 1 July 2014). Very recently the government has decided to implement the Safe Food Act 2013 from 1 February 2014 (The Daily Star, 28 January 2015).

\section{Conclusion}

Consumption of adulterated food items severely affects the human health by producing many acute and chronic diseases. It is very essential to stop food adulteration. The Government of the People's Republic of Bangladesh should eradicate the practices of food adulteration to save the lives of citizens. There are hundreds of laws in the country including the new antiformalin act 2014, but not many of them are enforced properly. Government should enact and implement these laws to ensure safe food without delay. Checking at the retail level only will not bring enough positive impacts. The whole supply chain from the producers and importers through wholesalers to retailers will have to be checked and cleaned. Regular monitoring by appropriate agencies should continue it in a sustainable manner for controlling food adulteration. Simultaneously, a consumer awareness campaign will have to be started. Adequate measures by the concerned authorities, civil societies, print and electronic media, social organizations and even consumers can make a difference to ensure food security and safe food for all. We hope this situation will change and our citizen will get safe food for a healthy life.

In the United States, Food and Drug Administration (FDA) has been established which is comprised of trained personnel with the capability of enforcement of laws to monitor quality of the foods and drugs available in the US market. If the Drug Administration of Bangladesh is reformed in similar fashion of FDA, then better control of adulteration of food and drug in Bangladesh will be possible for the welfare of our population.

\section{References}

Badrie, N., Sonia Y., Leon, D. and Talukder, M.R.A. 2006. Food adulteration management systems: Initiatives of Trinidad and Tobago, West Indies, Philippines and Bangladesh. (paper presented at Caribbean Agro-Economics Society 26th West Indies Agricultural Economic Conference, Puerto Rico, July 2006), p. 85.

Derek, L. 2013. Eight toxic foods: a little chemical education. http://pipeline.corante.com/archives/2013/06/21/eight_toxic _foods_a_little_chemical_education.php, Date of access: January 29, 2015

Dhaka Mirror, 23 August 2009. Iftars with lethal dyes haunt people. http://www.dhakamirror.com/headlines/iftars-withlethal-dyes-haunt-people/

Dhaka Tribune, 15 March 2014. Capital punishment for food adulterers needed. http://www.dhakatribune.com/safety/ 2014/mar/15/capital-punishment-food-adulterers-needed.

Directorate General of Health Services. 2012. Public health interventions by selected institutions.

FAO, 2010. Improving food safety, quality and food control in Bangladesh. Food inspection and enforcement in Bangladesh: current arrangements and challenges by Food and Agriculture Organization of the United Nations, October 2010. www.bdfoodsafety.org

Farooque, A.B.M. 2014. Asun rozar mashe khotikor rang meshano khabar borjon kori. The Bonik Barta, 9 July 2014 http://www.bonikbarta.com/2014-07-09/news/details /6891. html

Khan, M.A. 2014. Bitter truth: slow poisoning continues unabated. The Daily Star, 17 May, 2014. http://www.thedailystar.net/slow-poisoning-continues-unabated-24369

Leon, A.H. Combating food adulteration from a rights perspective. The Daily Star, http://www.thedailystar.net/ combating-food-adulteration-from-a-rights-perspective32252, 8 July, 2014. 
Mahfuz, M. 2014. Baro hat bidhi-nishedh tero hat vejal, The Daily Amader Shomoy, 2 July 2014. http://www.dainikamadershomoy.com/

Mahfuz, M. and Mahin, D. 2014. Bahari Iftarir Shomahar, The Daily Amader Shomoy, 1 July 2014, http://www.dainikamadershomoy.com/

Nath, D.K. 2014. Food or poison? bdnews24.com, May 9, 2014. http://opinion.bdnews24.com/2014/05/09/food-or-poison.

Parvez, S. 2014. The steps to clean food, The Daily Star, 22 May, 2014. Protection of the consumer rights in Bangladesh. http://www.assignmentpoint.com/business/ marketing-business/protection-consumer-rights-bangladesh. html.

Rahman, S.M., Hoque, M.A., and Talukder, M.R.A. 2005. Food security in Bangladesh: utilization, nutrition and food adulteration (paper presented at the National Workshop on Food security, Dhaka, Bangladesh, 19-20 October 2005), pp. 45-46.

Rimon, S.R. 2014. Iftari noi bish. The Bangladesh Protidin, 3 July 2014. http://www.bd-pratidin.com/index.php

The Daily Observer, 22 June 2014. Enforce existing laws against food adulteration. http://observerbd.com/details.php?id= 27183.

The Daily Prothom Alo, 1 July 2014. Khotikor formalin babohare shasti jabojjiban. http://www.prothom-alo. com/bangladesh/article/255880

The Daily Star, 1 July 2014. Anti-formalin bill okayed: chemical worries won't be over. http://www.thedailystar.net/newsarchive/chemical-worries-wont-be-over-31195.

The Daily Star, 1 November 2009. Trader fined for selling fish treated with formalin. http://archive.thedailystar.net/new Design/news-details.php?nid=103948.

The Daily Star, 11 August 2011. Food adulteration rings alarm bell. http://archive.thedailystar.net/newDesign/news-details. php?nid=198096.

The Daily Star, 12 July 2007. Adulterated ghee seized. http:// www.thedailystar.net/newDesign/news-details.php?nid $=66453$.
The Daily Star, 22 March 2014. Food safety remains under strain, New Food Act shouldn't be toothless. http://www.thedailystar.net/food-safety-remains-understrain-16632

The Daily Star, 28 July 2011. Two puffed rice factories fined Tk. 1 lakh. http://archive.thedailystar.net/newDesign/newsdetails.php?nid=196107.

The Daily Star, 30 January 2007. Traders fined for selling toxic chemicals as food colour. http://archive.thedailystar.net/ 2007/01/30/d70130013625.htm

The Daily Star, 4 August 2012. Bitter truth: rampant adulteration plays havoc. http://archive.thedailystar.net/newDesign/ cache/cached-news-details-244692.html

The Daily Star, 7 December 2008. Ghee of 10 BSTI-certified brands found adulterated. http://archive.thedailystar.net/ newDesign/news-details.php?nid $=66453$

The Daily Star, 28 January 2015. Safe food act to be effective from Feb 1. http://www.thedailystar.net/safe-food-act-to-beeffective-from-feb-1-61978

The Financial Express, 21 August 2014. Waging a war on food adulteration. http://www.thefinancialexpress-bd.com/ 2014/ 08/21/51533.

The Independent, 24 February 2014. Food adulteration poses 'too serious a threat' to public health. http://www. theindependentbd.com/food-adulteration-poses-too-seriousa-threat-to-public-health/ 24 February 2014.

The Independent, 19 August 2014. Growers face problems despite bumper production of pineapple. http://www. theindependentbd.com/index.php?option=com_content\&vie $\mathrm{w}=$ article $\& \mathrm{id}=223$.

WHO, 1988. Regional Office for Europe, "Indoor air quality: Radon report on a WHO working group," J. Environ. Radioact. 8, 73-91.

WHO, 2009. General information related to chemical risks in food. www.who.int foodsafety_chem general en index, 22 December 2009.

Wooster, G.A., Martinez, C.M. and Bowser, P.R. 2005. Human health risks associated with formalin treatments used in aquaculture: initial study. N. Am. J. Aquac. 67, 111-113. 